\title{
Association of periodontitis and chronic kidney disease in dogs
}

\author{
S. U. Nabi ${ }^{1}$, A. R Wani ${ }^{2}$, O. S. Shah ${ }^{3}$ and S. Dey ${ }^{1}$ \\ 1. Division of Veterinary Medicine, Indian Veterinary Research Institute, Izatnagar - 243122, Uttar Pradesh, India; \\ 2. Department of Veterinary Pharmacology And Toxicology, College of Veterinary Science, Assam Agricultural \\ University, Khanapara, Guwahati- 781022, Assam, India; 3. Department of Veterinary Medicine, SKUAST-K, \\ Srinagar- 192301, Jammu and Kashmir, India. \\ Corresponding author: Abdul Rakeeb Wani, email: etheralecho@gmail.com, Cell: +91-9906958601.
}

Received: 14-01-2014, Revised: 10-02-2014, Accepted: 12-02-2014, Re-revised: 07-06-2014, Published online: 13-06-2014

doi: 10.14202 /vetworld.2014.403-407

How to cite this article: Nabi SU, Wani AR, Shah OS and Dey S (2014) Association of periodontitis and chronic kidney disease in dogs, Veterinary World 7(6): 403-407.

\begin{abstract}
Aim: The purpose of our study is to study the etiopathogenesis of periodontitis in chronic kidney disease and to identify a correlation between periodontitis and chronic kidney disease, with the help of periodontal exaamination, ultrasonographic and hematobiochemical analysis.
\end{abstract}

Materials and Methods: 46 dogs with renal failure were studied and classified as presenting a slight (56.52\%), moderate (36.95\%) and severe (47.8\%) degree of periodontal disease.

Results: Marked gingival recession involving whole maxillary dental arcade, Oral mucosa ulcers and tissue necrosis and mobility of mandibular incisors was observed in dogs with chronic kidney disease. Dogs with normal renal function were observed to have minimal gingival recession of the mandibular teeth only.

Conclusion: In view of the causative association between periodontal infection, generalized inflammation and important systemic diseases like chronic kidney disease, we hypothesize that targeted prophylaxis and careful treatment of oral diseases can prevent the progression of renal failure

Keywords: biochemical parameters, chronic kidney disease, gingival recession, periodontitis.

\section{Introduction}

Periodontal disease (PD) is the most common oral disease in dogs that affects both health and quality of their life [1]. PD is defined as a plaque-inducing disease of any part of the periodontium, which includes the gingiva, periodontal ligament and alveolar bone [1]. It is considered as a factor that predisposes patients to bacteraemia [2]. In dogs suffering from periodon-titis, concurrence of kidney disease with periodontitis is considered a consequence of low-grade bacteraemia associated with periodontal disease [3]. However, clinical manifestation of bacteraemia is not well correlated with the causative agent or it may not be clinically apparent [2]

Several studies have evaluated the relation between PD and chronic renal failure in humans [4]. In dogs, PD has been related to morphological changes in renal glomeruli and interstitium [3]. There is some controversy between reported findings in dogs' relation between PD and chronic renal failure $[2,4]$.

Thus, the purpose of this study is to describe periodontal findings in dogs with naturally acquired chronic kidney disease (CKD) in comparison to otherwise, healthy dogs.

\section{Materials and Methods}

Ethical approval: Ethical approval was sought in advance and all the ethical principles were strictly

Copyright: The authors. This article is an open access article licensed under the terms of the Creative Commons Attribution License (http://creativecommons.org/licenses/by/2.0) which permits unrestricted use, distribution and reproduction in any medium, provided the work is properly cited. followed during the course of this study. The research and experimentation was carried out in accordance with the guidelines laid down by the International Animal Ethics Committee and in accordance with the local laws and regulations

Study animals: Subjects in the study consisted of 40 (20 females and 20 males) systemically healthy dogs (group I) and 46 dogs (21 females and 25 males) with renal failure (group II) that were attended in Referral Veterinary Polyclinic IVRI, Izatnagar. The healthy animals were selected from the healthy lot of experimental animals in the college. Canines having haemato-biochemical and ultrasonographic parameters within normal range were selected as healthy group. The CKD dogs' group included patients presenting creatinine level, Blood Urea Nitrogen (BUN) level and urine specific gravity above the normal range. The animals were between the ages of 7 to 10 years and Body weight of dogs in both groups ranged from 8 to $12 \mathrm{~kg}$. Dogs in healthy group were matched with respect to age, sex, breed and weight with dogs in renal failure group. Information related to the general health status and renal function was retrieved from the patient's record. To be included in the Normal renal function (NRF) or CKD group, dogs should have well characterized pocket formations.

Haematobiochemical analysis and ultrasonographic findings: Information related to the general health status and renal functions were assessed by haematobiochemical analysis and ultrasonographic findings. 


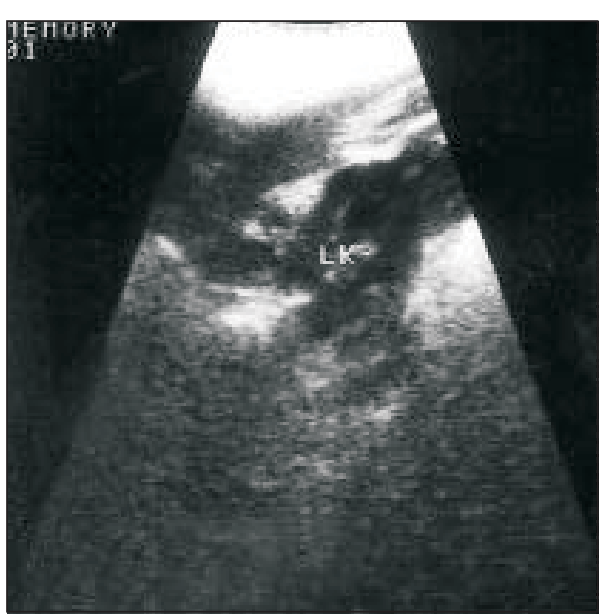

Figure-1: Chronic renal failureshowing loss of cortico-medullary definition.

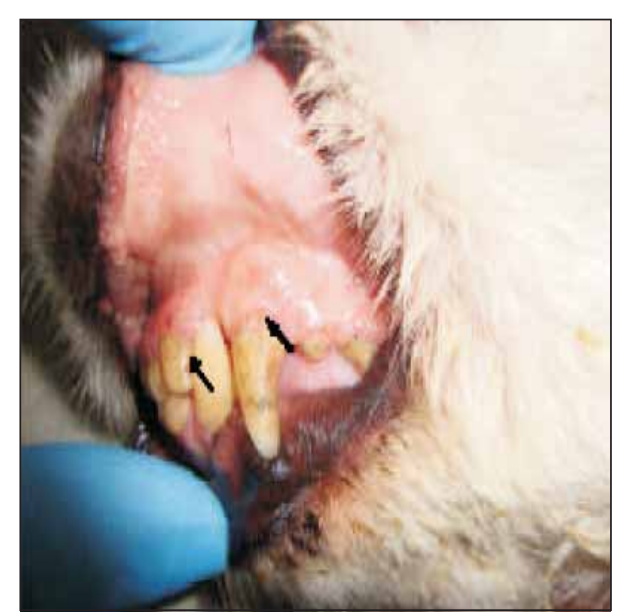

Figure-2 : Periodontitis (mild) discoloration of dental enamel with loss of gingival margin

Table-1: Comparison of periodontal complications among dogs with renal dysfunction and dogs with normal renal function.

\begin{tabular}{lccc}
\hline Variable & NRF (X \pm SD) & CRF (X \pm SD) & Student's t test \\
\hline Age (years) & $8-12$ & $8-12$ & - \\
Periodontal Destruction Index & $0.63 \pm 0.69$ & $0.85 \pm 1.05$ & 0.15 \\
Plaque Index & $0.64 \pm 0.53$ & $0.93 \pm 0.57$ & 0.14 \\
Gingival Index & $0.53 \pm 0.57$ & $0.92 \pm 0.63$ & 0.20 \\
Retention Index & $0.48 \pm 0.55$ & $0.88 \pm 0.57$ & 0.15 \\
\hline
\end{tabular}

Table-2: Comparison of severity of periodontal disorders among dogs with renal dysfunction and dogs with normal renal function.

\begin{tabular}{|c|c|c|c|c|c|c|}
\hline Variable & CRF - SL (X $\pm S D)$ & NRF - SL $(X \pm S D)$ & Student's t test & CRF - S (X $\pm S D)$ & NRF - S (X ISD ) & Student's $\mathrm{t}$ test \\
\hline PDI & $0.62 \pm 0.15$ & $0.31 \pm 0.13$ & $0.01^{*}$ & $1.20 \pm 0.75$ & $0.46 \pm 0.25$ & $0.01^{*}$ \\
\hline $\mathrm{PI}$ & $0.84 \pm 0.33$ & $0.43 \pm 0.18$ & $0.01^{*}$ & $0.94 \pm 0.66$ & $0.40 \pm 0.30$ & $0.01^{*}$ \\
\hline GI & $0.62 \pm 0.47$ & $0.38 \pm 0.25$ & $0.01^{*}$ & $1.34 \pm 0.60$ & $0.50 \pm 0.32$ & $0.01^{*}$ \\
\hline RI & $0.64 \pm 0.47$ & $0.32 \pm 0.27$ & $0.01^{*}$ & $0.98 \pm 0.39$ & $0.23 \pm 0.18$ & $0.01^{*}$ \\
\hline
\end{tabular}

* Significant $(\mathrm{P}<0.05)$. PDI - periodontal destruction index, PI - plaque index, GI - gingivitis index, RI - retention index. CRF chronic renal failure, NRF - normal renal function, SL - slight periodontitis, $\mathrm{S}$ - severe periodontitis

The data were expressed as mean \pm standard deviation and data was normally distributed. All oral examinations were carried out by a single examiner and included evaluation of bacterial plaque, gingivitis, gingival recession, pocket, calculus, dental mobility, dental loss, and oral ulcers. The examination included all teeth. Dental recordings were made according to WHO criteria [5]. The extent of pocket formation (from the free gingival margin to the bottom of the pocket) and the extent of the recession (from the free gingival margin to the cement-enamel junction) were measured on facial aspects of teeth. Teeth mobility was assessed by digital pressure and was used as an indicator for supporting bone structure loss and determination of the periodontal destruction index (PDI) $[6,7]$.

Statistical analysis: All data were collected in an appropriate form. The number of teeth present was recorded. Gingival Index (GI) and Plaque Index (PI) were scored using the systems described by Loe et al [8], however, for our study only facial aspects of teeth were considered. A modified PDI was used, where: PDI $=$ Pocket depth $(\mathrm{mm})+$ Recession $(\mathrm{mm})$ [9]. Periodontal disease was graded on the basis of the worst teeth affected, according to pocket depth. Periodontitis was graded as slight (pockets $>2$ and $<3 \mathrm{~mm}$ ), moderate (pockets $>3$ and $<5 \mathrm{~mm}$ ) and severe (pockets $>5 \mathrm{~mm}$ ).
This study considered the normal sulcus in dogs as being $<2 \mathrm{~mm}$, as described by Gorrel and Bierer [10]. Results were expressed as mean and standard deviation. Comparisons between groups were made using Student's t test as shown in Table- 1 and 2.

\section{Results}

In our study the relatively large numbers of dogs were selected in each group. The mean (median) age, weight, proportion of dogs by gender, neuter status, and breed in each cohort were calculated. Statistically non significant differences between groups by age, weight, gender, nutritional status and breed were reported as efforts were made to match dogs in above mentioned demographic parameters between diseased group and normal renal function group.

The present study observed a significant association between PD and renal failure. Forty six dogs with renal failure were classified as having a slight $(56.52 \%)$, moderate $(36.95 \%)$ and severe $(47.8 \%)$ degree of periodontal disease (Figure-1, 2, 3, 4 and 5). Marked gingival recession was observed in maxillary teeth of dogs with chronic renal failure than dogs with normal renal function. Increasing severity of periodontal disease was significantly associated with increasing severity of renal failure. (Table-2, Figure- 2 and 3).

Haematobiochemical analysis and ultrasono- 


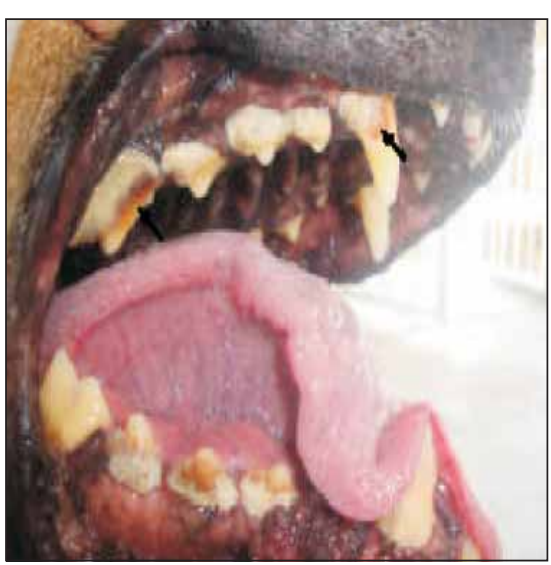

Figure-3: Periodontitis (moderate) excessive wearing and increased mobility of teeth

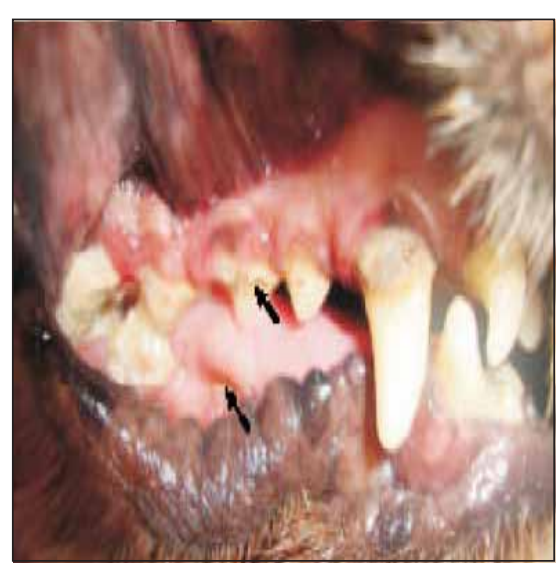

Figure-4: Periodontitis (severe) ulceration with excessive gingival recession

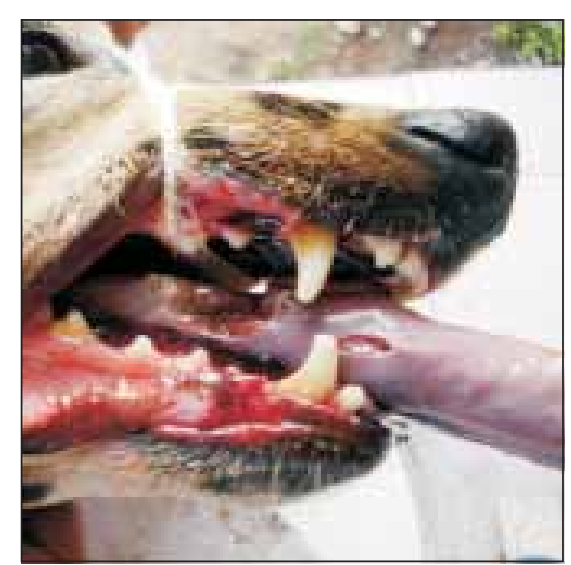

Figure-5: Ulcerative lesion in tongue in dog suffering from chronic renal failure

Table-3: Haematological changes in dogs with kidney dysfunction

\begin{tabular}{lll}
\hline Parameters & Group I & Group II \\
\hline Total Erythrocyte Count $\left(\times 10^{6}\right.$ cells/ $\left.\mu \mathrm{l}\right)$ & $6.13 \pm 0.501$ & $4.19 \pm 0.35 * *$ \\
Hemoglobin $(\mathrm{g} / \mathrm{dl})$ & $13.17 \pm 0.77$ & $10.56 \pm 0.97 *$ \\
Packed Cell Volume $(\%)$ & $46.17 \pm 2.53$ & $31.14 \pm 2.77 * *$ \\
Mean Corpuscular Volume(fl) & $75.30 \pm 2.55$ & $74.64 \pm 2.22$ \\
Mean Cell Haemoglobin $(\mathrm{pg})$ & $21.97 \pm 2.99$ & $25.84 \pm 1.88$ \\
Mean Corpuscular Haemoglobin Concentration $(\%)$ & $28.5 .30 \pm 2.64$ \\
\hline
\end{tabular}

Values with superscript * and ** differ significantly $(P<0.05)$ between the groups.

Table-4: Biochemical changes in dogs with kidney dysfunction

\begin{tabular}{|c|c|c|}
\hline Parameters & Group I & Group II \\
\hline Creatinine (mg/dl) & $0.64 \pm 0.08$ & $4.51 \pm 0.97^{* *}$ \\
\hline Cholesterol (mg/dl) & $253.22 \pm 21.72$ & $265.41 \pm 21.82$ \\
\hline Blood Urea Nitrogen (mg/dl) & $11.87 \pm 0.93$ & $45.31 \pm 3.89^{* *}$ \\
\hline Albumin (g/dl) & $3.14 \pm 0.28$ & $2.81 \pm 0.29$ \\
\hline Glucose (mg/dl) & $87.88 \pm 9.86$ & $93.47 \pm 9.80$ \\
\hline $\operatorname{ALP}(U / L)$ & $117.52 \pm 17.99$ & $341.05 \pm 25.39$ ** \\
\hline Phosphorus (mg/dl) & $2.10 \pm 0.28$ & $6.32 \pm 0.79^{* *}$ \\
\hline Calcium (mg/dl) & $11.53 \pm 1.0$ & $147.56 \pm 0.92^{\star *}$ \\
\hline AST (U/L) & $61.52 \pm 7.92$ & $105.76 \pm 9.79$ \\
\hline $\operatorname{ALT}(U / L)$ & $37.05 \pm 4.44$ & $63.70 \pm 5.14^{* *}$ \\
\hline Total billirubin (mg/dl) & $2.53 \pm 0.65$ & $3.63 \pm 0.57$ \\
\hline Total protein $(\mathrm{g} / \mathrm{dl})$ & $6.30 \pm 0.26$ & $5.76 \pm 0.22$ \\
\hline Globulin (g/dl) & $4.04 \pm 0.24$ & $2.84 \pm 0.32$ \\
\hline
\end{tabular}

Values with superscript $* *$ differ significantly $(P<0.05)$ between the groups.

graphic findings: Information related to the general health status and renal functions were assessed by haemato-biochemical analysis and ultrasonographic findings. The data were expressed as mean \pm standard deviation and data was normally distributed. The control group included patients presenting creatinine level $(0.64 \pm 0.08 \mathrm{mg} / \mathrm{dl})$, BUN level $(11.87 \pm 0.93$ mg.dl), urine specific gravity $(1.025 \pm 0.018)$, Total Erytrocyte count ( $4.19 \pm 0.35$ million), haemoglobin $(10.56 \pm 0.98 \mathrm{mg} / \mathrm{dl})$, alkaline phosphatase (117.52 $\pm 17.99 \mathrm{U} / \mathrm{L})$, phosphorus $(2.10 \pm 0.28 \mathrm{mg} / \mathrm{dl})$ albumin $(3.14 \pm 0.28 \mathrm{mg} / \mathrm{dl})$ and total protein $(6.30 \pm 0.26 \mathrm{mg} / \mathrm{dl})$ (table 3 and 4).The renal failure dogs group included patients presenting creatinine level $(7.51 \pm 0.97 \mathrm{mg} / \mathrm{dl})$, Blood Urea Nitrogen level $(25.31 \pm 3.89 \mathrm{mg} / \mathrm{dl})$, urine specific gravity $(1.007 \pm 0.017)$, Total Erytrocyte count $(4.19 \pm 0.35$ million $)$ haemoglobin $(10.56 \pm 0.98 \mathrm{mg} / \mathrm{dl})$ alkaline phosphatase $(341.06 \pm 25.39 \mathrm{U} / \mathrm{L})$, phosphorus $(6.32 \pm 0.79 \mathrm{mg} / \mathrm{dl})$ albumin $(2.81 \pm 0.29 \mathrm{mg} / \mathrm{dl})$ and total protein $(5.76 \pm 0.23 \mathrm{mg} / \mathrm{dl})$, (Table-3 and Table-4).
Hemato-biochemical findings were supplemented by ultrasonographic evidence of chronic kidney disease (Figure-1).

Dogs in renal failure group had involvement of the whole maxillary dental arcade while dogs with normal renal function group presented minimal gingival recession of the mandibular teeth only (Figure-2). Non uniform Mobility of mandibular incisors was observed in dogs with renal failure, whereas dogs with normal renal function presented normal, minimal and uniform mobility distribution of mandibular teeth.

Analysis of GI, PI, retention index (RI) and PDI between groups were significant. All indexes presented a higher value in dogs with chronic kidney disease when compared to dogs with normal renal function. In severe periodontitis, despite the fact that significant differences were observed, dogs with chronic kidney disease presented a higher gingivitis index than dogs with normal renal function (Table-3 and 4). 


\section{Discussion}

There was a significant relationship between severity of PD and markers of renal failure in dogs that belong to renal failure group. The severity of PD was positively related to the incidence of a clinical diagnosis of CKD. Our findings in dogs are consistent with a positive association between $\mathrm{PD}$ and CKD in humans [11]. However, studies in humans have generally been cross-sectional and therefore confounding by shared demographic and environmental risk factors for periodontal and renal disease including infection and inflammation [12]. The mechanisms by which PD may increase the risk of CKD are not known. Evidence suggest that periodontitis results in subclinical systemic inflammation which leads to secondary renal hypoxemia, progressive renal damage, and CKD [12]. Previous longitudinal study in dogs reported a significant relationship between the severity of PD and non-specific biomarkers of inflammation [13]. Interestingly, although PD severity among dogs in the present study was associated with increasing risk of azotemic CKD, previous longitudinal study in dogs reported a significant relationship between the severity of PD and non-specific biomarkers of inflammation such as white blood cell count and the percentage of monocytes in peripheral blood [13]. Statistical association between PD severity and histological lesions in the heart and kidneys of dogs at necropsy has also been reported [14]. Periodontitis as a chronic systemic disorder increases both local and systemic inflammation and associated markers. Such inflammation can also cause systemic endothelial dysfunction $[15,16,17]$. In Kidney tissue these inflammatory factors may have impact on the glomerular endothelium leading to renal failure which is supported by studies $[18,19]$ which observed that treatment of PD has positive effect as a surrogate marker for clinical renal disease.

In our study dogs with CKD presented a higher GI than dogs with normal renal function, as observed in uremic patients [20]. Deficient or diminished function of polymorphonuclear lymphocytes appears to be related to the progression of severe PD and hence higher GI value [21]. At early stages, dental plaque accumulation was much more evident involving the mandibular teeth. In severe periodontitis there was a generalized increase in dental plaque accumulation along the mandibular arcade, with a corresponding increase in gingival inflammation [22, 23]. Periodontitis results in increased systemic inflammatory response which results in derangement in functioning of various organs including kidney [23].

There were some limitations of our study: firstly, our study was cross-sectional study that does not allow for causal inference, and reverse causation (CKD causing periodontal disease), or the coexistence of the two due to common underlying risk factors, cannot be excluded. Secondly, like all observational studies, our study is subject to possible confounding observations due to unknown or unmeasured factors (premedication, stage of pregnancy, daily water intake and nutrition). Thus, longitudinal studies are needed to determine to what extent periodontal disease is a true risk factor for chronic renal failure and to what extent treatment of periodontal disease affects the kidney function over time $[24,25]$. Despite these limitations in our study, there is some evidence that warrant considering severe periodontitis as risk factor of chronic renal failure. Thus, in view of the causative association between periodontal infection, generalized inflammation and important systemic diseases like chronic renal failure, we hypothesize that targeted prophylaxis and careful treatment of oral diseases can be preventive in progression of renal failure.

\section{Conclusion}

In our study, we demonstrated an association of CKD by using battery of renal markers and employed an updated definition of periodontitis while focusing on severity of PD. In our study, we found a causative association between periodontal infection and CKD that warrant considering severe periodontitis as risk factor of CKD.

\section{Authors' contributions}

SUN and SD implemented the study design. SUN and ARW recorded and analysed the data. ARW and OSS drafted and revised the manuscript. All authors read and approved the final manuscript.

\section{Acknowledgements}

The authors are thankful to the Director, Indian Veterinary Research Institute, Izatnagar, India for providing facilities and funds to carry out the present work.

\section{Competing interests}

The authors declare that they have no competing interests.

\section{References}

1. Harvey, C.E. (2005) Management of periodontal disease: Understanding the options. Vet Clin North Am Small Anim Pract.. 35(4): 819-836.

2. Calvert, C.A., Greene, C.E. and Hardie, E.M. (1985) cardiovascular infections in dogs: epizootiology, clinical manifestations, and prognosis. $J$ Am Vet. Med. Assoc, 187(6): 612-616.

3. De Bowes, L.J., Mosier, D., Logan, E., Harvey, C.E., Lowry S. and Richardson, D.C. (1996) Association of periodontal disease and histopathologic lesions in multiple organs from 45 dogs. J Vet Dent. 13(2): 57-60.

4. Dasanayake, A.P. (2009) C-reactive protein levels are elevated in patients with periodontitis and their CRP levels may go down after periodontal therapy. J Evid Based Dent Pract. 9:21-22.

5. World Health Organization (WHO), (2011) Oral health surveys, $5^{\text {th }}$ edn. Geneva, p567-569.

6. Jaffe, E.C. and Roberts, G.J. (1986) Dental findings in chronic renal failure. Brit Dent. J. Hants, 160(1): p18-20.

7. Tollefsen, T. and Johansen, J.R. (1985) Periodontal status in patients before and after renal allotransplantation. $J$ Periodont Res. 20: 227-236.

8. Löe, H. Anerud, A. Boysen, H and Morrison E. (1967) Natural history of periodontal disease in man. Rapid, 
moderate and no loss of attachment in Sri Lankan laborers 14 to 46 years of age. J Clin Periodontol. 13(5):431-45.

9. Oshrain, H.I., Mender, S. and Mandel, I.D. (1979) Periodontal status of patients with reduced immunocapacity. JPeriodontol 50(4): 185-188.

10. Gorrel, C. and Bierer, T.L. (1999) Long term effects of a dental hygiene chew on the periodontal health of dogs. J Vet Dent, 16 (3) 109-113.

11. Loe, K.T. (2012) the neutrophil: Mechanisms of controlling periodontal bacteria. J Periodontol, 62: 761-774.

12. Kshirsagar, A.V., Bomback, A.S., Bang, H., Gerber, L.M., Vupputuri, S. and Shoham, D.A. (2008) Association of C reactive protein and micro albuminuria (from the National Health and Nutrition Examination Surveys, 1999 to 2004). Am. J. Cardiol. 101: 400-406.

13. Scannapieco, F.A. and Panesar, M. (2008) Periodontitis and chronic kidney disease. J. Periodontol. 79 (9):1617-1619.

14. Glickman, L.T., Glickman, N.W., Moore, G.E., Goldstein, G.S. and Lewis, H.B. (2009) Evaluation of the risk of endocarditis and other cardiovascular events on the basis of the severity of periodontal disease in dogs. J. Am. Vet. Med. Assoc.234 (4): 486-494.

15. De Bowes, L.J., Mosier, D., Logan, E., Harvey, C.E., Lowry S. and Richardson, D.C. (1996) Association of periodontal disease and histopathologic lesions in multiple organs from 45 dogs. $J$ Vet Dent. 13(2): 57-60.

16. Eisner, E.R. (1989) periodontal disease in pets: the pathogenesis of a preventable problem. Vet. Med. Lenexa. 84(1): 97-104.

17. Karjalainen, K. and Knuuttila, M. (1996) the onset of diabetes and poor metabolic control increases gingival bleeding in children and adolescents with insulin-dependent diabetes mellitus. JClin Periodontol, 23(12):1060-1067.

18. Souza, C.M., Braosi, A.P.R. and Luczyszyn, S.M. (2010) Association between vitamin D receptor gene polimorphisms and susceptibility to chronic kidney disease and periodontitis. Blood Purifi. 25: 411-419.

19. Yamalik, N. (1991) the histological investigation of gingival from patients with chronic renal failure, renal transplants, and periodontitis: A light and electron microscopic study. $J$. Periodontol, Chicago, 62(12): 737-744.

20. Yoshihara, A., Seida, Y. and Hanada, N. (2010) A longitudinal study of the relationship between periodontal disease and bone mineral density in community-dwelling older adults. J Clin. Periodontol. 31: 680-684.

21. Taylor, G.W., Burt, B.A. and Becker, M.P (1998). Noninsulin dependent diabetes mellitus and alveolar bone loss progression over 2 years. J Periodontol 69(1):76-83.

22. Wautier, J.L. and Guillausseau, P.J.(1998) Diabetes, advanced glycation endproducts and vascular disease. Vasc Med.3 (2):131-137.

23. Craig, R.G. (2008) Interactions between chronic renal disease and periodontal disease. Oral Dis. 14: 1-7.

24. Rahman, M.M., Çaglayan, F. and Rahman, B. (1992) Periodontal health parameters in patients with chronic renal failure and renal transplants receiving immunosuppressive therapy. J. Dent., 34: 265-272.

25. Glickman, L.T., (2011) Association between chronic azotemic kidney disease and the severity of periodontal disease in dogs. Pre. Vet. Med, 2011.99(4): 193-200. 